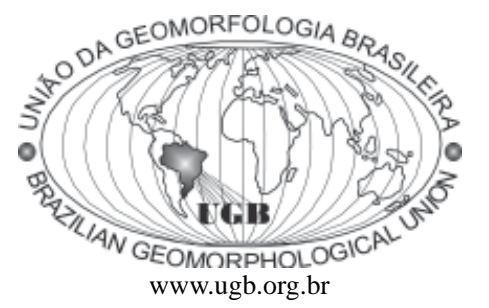

\title{
CARACTERIZAÇÃO DA REDE DE DRENAGEM NA PORÇÃO LESTE DA ILHA DO MARAJÓ E IMPLICAÇÕES TECTÔNICAS
}

\author{
Lena Simone Barata Souza \\ Universidade de São Paulo/Instituto de Geociências-Curso de Pós-Graduação em Geoquímica e Geotectônica \\ (USP/IGc-CPGG ) - Rua do Lago, 562, Cidade Universitária, São Paulo, SP, Brasil - \\ CEP 05508-900 - e-mail: lenabarata@yahoo.com.br,
}

\author{
Dilce de Fátima Rossetti \\ Instituto Nacional de Pesquisas Espaciais/Divisão de Sensoriamento Remoto (INPE/DSR), Caixa Postal 515, São José \\ dos Campos, SP, Brasil - CEP 12245-970 - e-mail: rossetti@dsr.inpe.br
}

\begin{abstract}
Resumo
A análise de bacias de drenagem, combinada com dados de sensoriamento remoto e cartográficos, fornece informações significantes para o reconhecimento de lineamentos morfoestruturais e para a detecção de feições tectônicas com expressão na paisagem atual. Este procedimento foi aplicado no estudo de três bacias de drenagem do leste da Ilha do Marajó, correspondentes aos rios Arari, Camará e Paracauari. Todas estas bacias mostram evidências de anomalias morfoestruturais, incluindo-se principalmente: mudanças rápidas no padrão de drenagem dentro de uma mesma bacia, variando de treliça, retangular, multibacinal a subparalelo; canais retilíneos comumente conectados em ângulos retos; canais fortemente sinuosos que se tornam retilíneos; meandros localizados; e bacias altamente assimétricas. Anomalias de drenagem, consistindo em frequentes desvios de direção formando ângulos retos e meandros isolados e comprimidos, são também reconhecidas na paleodrenagem preservada neste setor da ilha. Com base na densidade dos lineamentos estruturais, pode-se reconhecer dois compartimentos morfoestruturais. O compartimento I é localizado na porção centro-leste da área de estudo, onde ocorre densidade de lineamento alta com duas direções preferenciais para NW-SE e NE-SW. O compartimento II, correspondente ao restante da área, apresenta densidade de lineamentos variando entre muito baixa a média e com orientação principal para NE-SW. As características morfoestruturais dos sistemas de drenagem atual e pretérita permitem sugerir área com forte controle tectônico. A deformação tectônica pode refletir reativação de falhas de direções principais NW-SE e NE-SW, melhor registradas no compartimento I.
\end{abstract}

Palavras-chave: lineamentos morfoestruturais, tectônica, Ilha do Marajó.

\begin{abstract}
Analysis of drainage basins combining remote sensing and cartographic data provides significant information for the recognition of morphostructural lineaments and for the detection of tectonic features expressed in the modern landscape. This approach was applied to study three drainage basins from eastern Marajó Island, corresponding to the Arari, Camará and Paracauari rivers. These basins show evidence of morphostructural anomalies, mainly including: rapid changes in patterns that range from trellis, rectangular, multibasin to sub-parallel; channels that are connected in straight angles; rapid changes from highly sinuous to straight channels; localized meandering; and highly asymmetric basins. Drainage anomalies consisting of frequent channel deviation forming straight angles, as well as isolated and compressed meanders, are also recognized in the paleodrainage preserved in this sector of the island. With basis on the density of morphostructural lineament, it was possible to recognize two morphostructural compartments. Compartment I is localized in the center-east
\end{abstract}


portion of the study area and displays high lineament density trending preferentially to NW-SE and NE-SW. Compartment II, corresponding to the remaining of the area, shows lineament density ranging from low to medium, and mostly NE-SW trending. The morphostructural characteristics of both the modern and ancient drainage allow suggest that the study area had strong tectonic control. Tectonic deformation might reflect reactivation of mainly NW-SE and NE-SW trending faults, recorded better in the compartment I.

Keyworks: morphostructural lineaments, tectonics, Marajó Island.

\section{Introdução}

A análise de sistemas de drenagem tem sido de grande utilidade como ferramenta para a identificação de feições tectônicas em diferentes contextos geológicos (Salvi 1995; Zovoili et al. 2004; Delcaillau et al. 2006; Malik \& Mohanty 2007; Peters \& Van Balen 2007; El Hamdouni et al. 2008; García-Tortosa et al. 2008; Shtober-Zisu et al. 2008; Singh \& Tandon 2008; Tsodoulos et al. 2008; Pedrera et al. 2009). Este tipo de investigação, que pode ser auxiliada com o uso de recursos de sensoriamento remoto, é de interesse particularmente em áreas onde há pouca disponibilidade de afloramentos. Este é o caso da Região Amazônica, onde a baixa topografia desfavorece exposições naturais e, portanto, a caracterização direta de estruturas tectônicas. O registro da influência tectônica no desenvolvimento de sistemas de drenagem, tanto atuais, quanto passados, em áreas amazônicas, tem sido crescente (Sternberg 1950; Correa et al. 1974; Bemerguy 1981 e 1997; Latrubesse \& Rancy 1998; Souza Filho 2000; Souza Filho \& El Robrini 2000; Bemerguy et al. 2002; Bezerra 2003; Almeida-Filho \& Miranda 2007).

A Ilha do Marajó é uma área do baixo Amazonas cuja origem e evolução tem sido diretamente relacionada com reativações de falhas tectônicas durante o final do Cenozóico (Costa et al. 2001; Rossetti et al. 2007 e 2008a, b). De acordo com esses autores, este processo teria sido responsável, também, pela deposição de volume expressivo de sedimentos quaternários na ilha. Movimentações tectônicas teriam afetado, em especial, a margem leste da ilha, onde a captura do rio Tocantins por falhas transcorrentes de direção principal NE-SW teria culminado com sua separação do continente (Rossetti \& Valeriano 2007). Estudo de caráter regional definiu a Ilha do Marajó como parte do Compartimento Tectônico Marajoara, com feixes de falhas normais sintéticas e antitéticas NW-SE, segmentadas por falhas transcorrentes (compartimentais e de transferência) NE-SW e ENE-WSW (Bemerguy 1997).

Apesar dos trabalhos anteriores realizados na Ilha do Marajó já terem destacado o efeito de reativações tectônicas na sedimentação quaternária e no desenvolvimento da paisagem atual, faltam estudos detalhados que possibilitem demonstrar, de maneira inequívoca, a influência de atividades tectônicas no desenvolvimento de seus sistemas de drenagem.
Exceção foi uma análise prévia da drenagem no sudoeste da ilha, que mostrou predomínio de lineamentos morfoestruturais de direções NE-SW, NW-SE e, subordinadamente E-W, atribuídos a falhas tectônicas (Mantelli 2009). Com exceção desse trabalho, existe apenas um outro que reúne dados sedimentológicos e morfoestruturais da porção leste da ilha visando relacionar feições deformacionais sin-deposicionais com causa tectônica (Rossetti et al. 2007).

O presente trabalho tem como objetivo disponibilizar novas informações que possibilitem testar a hipótese de evolução dos sistemas fluviais da Ilha do Marajó por reativação de falhas tectônicas durante o Quaternário. Para isto, procedeu-se com a caracterização e análise de bacias de drenagem no leste da Ilha do Marajó (Figura 1), bem como com o mapeamento de morfologias associadas a paleocanais, com o intuito de reunir parâmetros derivados dos lineamentos morfoestruturais, das anomalias de drenagem e da comparação entre sistemas de drenagem abandonadas e atuais. O presente estudo morfológico contém informações relevantes que contribuem significativamente para se discutir a evolução da Ilha do Marajó durante o Quaternário.

\section{Caracterização da Área de Estudo}

\section{Fisiografia}

A Ilha do Marajó situa-se no nordeste do Estado do Pará, margem direita do baixo Amazonas, onde faz parte de um complexo flúvio-marinho de $49.606 \mathrm{~km}^{2}$. A ilha é limitada pelos rios Amazonas (oeste), Pará (sul), Tocantins-Baía do Marajó (leste), e pelo Oceano Atlântico (norte) (Figura 1). A área de estudo situa-se no leste da ilha, e faz parte dos municípios de Salvaterra, Cachoeira do Arari, Joanes e Ponta de Pedras.

A classificação climática de Köppen para a Ilha do Marajó é do tipo Ami-tropical chuvoso (Teixeira Neto et al. 1991; DNMET 1992). O clima equatorial úmido caracterizase por temperatura média em torno de $27^{\circ} \mathrm{C}$, com mínima superior a $18^{\circ} \mathrm{C}$ e máxima de $36^{\circ} \mathrm{C}$, havendo alta pluviosidade e umidade nos seis primeiros meses do ano. Os solos são, em geral, hidromórficos indiscriminados e hidromórficos gleyzados (Correa et al. 1974). 


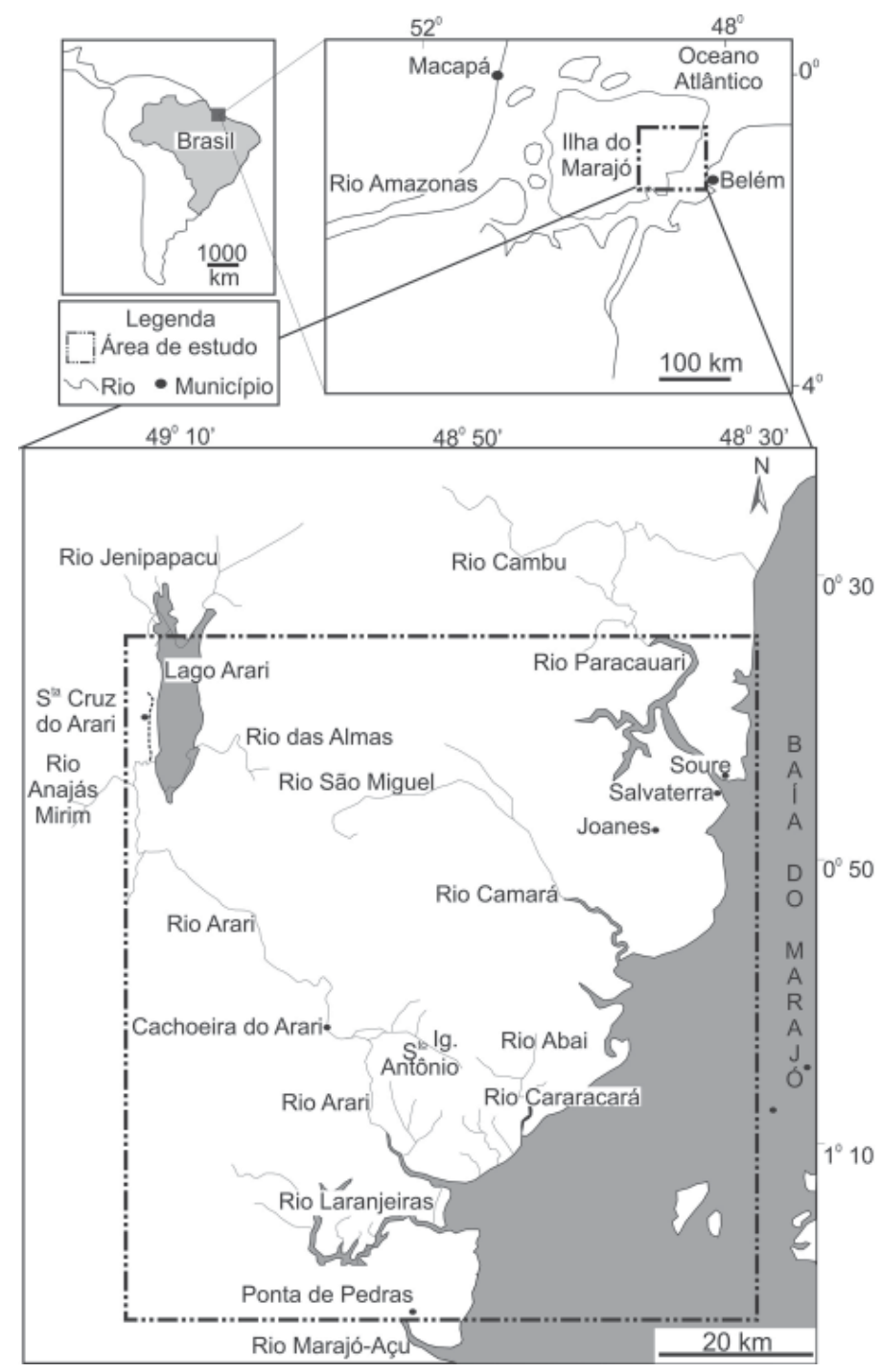

Figura 1 - Localização da área de estudo na porção leste da Ilha do Marajó.

A topografia da Ilha do Marajó é dominantemente plana e sujeita a inundações sazonais durante estações chuvosas, sendo caracterizada por planícies fluviais colmatadas nas porções leste e oeste, e superfícies pediplanadas na porção central. Dados de altimetria derivados de mapas e cartas topográficas são raros ou inexistentes, sendo as estimativas de cotas variando entre 2 e 42m. Modelos digitais de elevação derivados da Shuttle Radar Topography Mission-SRTM indicam cotas entre 4 e 6 m na porção leste da ilha, e entre 6 e $38 \mathrm{~m}$ em sua porção oeste, com média de $12 \mathrm{~m}$ para toda a ilha (Rossetti \& Valeriano 2007). Estes dados refletem não apenas a altitude, mas também a vegetação, que se caracteriza, na porção ocidental, por floresta do tipo ombrófila densa aluvial e densa de terras baixas e, na porção oriental, por campo natural inundável, savana parque ou arborizada, campo cerrado e campo de murundu ou “mondongo" (IDESP 1974).

\section{Contexto Geológico}

A Ilha do Marajó é inserida, em sua porção oeste, no Sistema de Graben do Marajó (SGM) e, em sua porção leste, na Plataforma do Pará (PP). O SGM, localizado na parte norte do Estado do Pará, abrange quase $50000 \mathrm{~km}^{2}$ e possui forma alongada de direção NW-SE. Este graben tem feições geológicas e geomorfológicas características de distensão mesozóica e neotectônica pós-miocênica. A disposição do depocentro do SGM sugere arquitetura em semi-graben, com formação de sub-bacias separadas por falhas direcionais ENE e NE-SW (Mexiana a norte, Limoeiro ao centro, e Cametá e Mocajuba a sul; Villegas 1994) (Figura 2). O arcabouço estratigráfico desse sistema de graben consiste em um pacote de rochas sedimentares formadas desde o Eocretáceo até o recente, que atinge espessura de até $11 \mathrm{~km}$. 


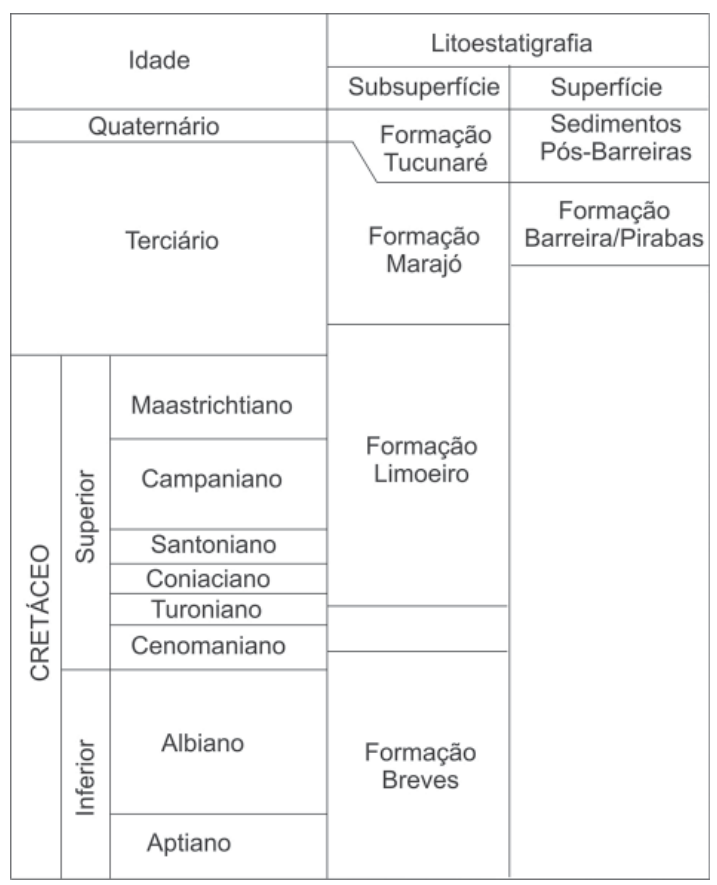

Figura 2 - Síntese da organização estratigráfica da área de estudo (modificada de Rossetti \& Valeriano, 2007).

A PP corresponde a uma extensa área do embasamento que permaneceu tectonicamente estável entre as bacias paleozóicas do Amazonas e Parnaíba, estas separadas pelos arcos de Gurupá e Tocantins. Pequenas fossas com profundidades de até $3.500 \mathrm{~m}$ ocorrem no interior desta plataforma (Rezende \& Ferradaes 1971).

Em superfície, a porção leste da ilha é composta por depósitos miocênicos) (sucessão Pirabas/Barreiras) e depósitos pleistocenos-holocênicos, designados genericamente de Sedimentos Pós-Barreiras (Figura 2). A Formação Pirabas consiste em uma sucessão de fácies carbonáticas com intercalações de folhelhos e arenitos, que são atribuídos a ambiente marinho raso e plataformal restrito, bem como lagunas e mangues conectados a ambiente estuarino (Góes et al. 1990). A Formação Barreiras é constituída de arenitos maciços e estratificados, argilitos laminados e maciços, além de pelitos com acamamentos heterolíticos, cuja origem é atribuída a ambiente transicional estuarino (Arai et al. 1988; Rossetti et al. 1989; Rossetti 2000; Rossetti 2001). Os Sedimentos Pós-Barreiras englobam arenitos finos e médios, maciços e de cor amarela, atribuídos a processos gravitacionais e eólicos (Rossetti et al. 1989).

\section{Métodos}

Para a caracterização morfoestrutural, procedeu-se com a elaboração do mapa de drenagem, partindo-se de mapas digitais correspondentes à Folha SA-22 (Belém), elaborados pelo Instituto Brasileiro de Geografia e Proteção da Amazônia (SIPAM). Estes dados foram complementados com a extração visual de drenagens, a partir da análise de imagens Landsat 5-TM (Refs 224-060 e 225061, INPE) e Landsat 7-ETM (Refs 223-060 e 223-061, GLCF), adquiridas em Agosto de 2001. Estas cenas foram escolhidas por mostrarem a área de estudo excepcionalmente livre de nuvens.

As imagens Landsat foram processadas no aplicativo SPRING, estabelecendo-se esquemas de composição de bandas. A composição $4(\mathrm{R}), 5(\mathrm{G})$ e 7 (B) foi a que melhor possibilitou a visualização da rede de drenagem, tendo sido, portanto, escolhida para este mapeamento. Esta composição possibilitou, ainda, o mapeamento de feições morfológicas relacionadas a drenagens abandonadas antes do estabelecimento da drenagem atual, cuja análise foi importante para a complementação deste estudo.

Apesar de limitações devidas à topografia extremamente baixa, modelo de elevação digital-SRTM foi complementarmente utilizado no reconhecimento de paleocanais. Esses dados foram obtidos na banda $\mathrm{C}$ por radar interferométrico InSAR durante missão conjunta da National Aeronautics and Space Administration (NASA) e National Imagery and Mapping Agency (NIMA), em fevereiro de 2000. As informações, de 90m de resolução, são de acesso gratuito nos sites http://edc.usgs.gov/ srtm/data/obtainingdata.html ou ftp://e0srp01u.ecs.nasa. gov/. Os dados foram processados no aplicativo Global Mapper, utilizando-se ferramentas de criação de paletas de cores e tons de cinza para representar classes topográficas, definidas de forma personalizada para melhor possibilitar a visualização das morfologias de interesse para este estudo.

Com base no mapa de drenagem, procedeu-se com a extração manual dos lineamentos de drenagem. Os mapas de densidade destes elementos foram derivados de ferramentas de análise de bacias de drenagem disponíveis no aplicativo ArcGIS. Os diagramas em roseta, representativos das orientações dos lineamentos morfoestruturais, foram obtidos por análise automática no aplicativo SPRING. A atribuição de propriedades e anomalias de drenagem a fatores tectônicos seguiu critérios apresentados em Howard (1967), Holmes (1965), Christofoletti (1981), Kehew (1995), Berger (1994), Bloom (1991), Deffontaines \& Chorowicz (1991), Summerfield (1991). 


\section{Caracterização das Bacias de Drenagem}

A Figura 3 apresenta o mapa de drenagem utilizado na presente análise, e a Figura 4 o mapa de densidade de drenagem derivado desse produto. A drenagem da área de estudo é representada por três bacias principais, correspondentes aos rios Arari, Camará e Paracauari. A densidade de drenagem foi categorizada em 5 classes relativas (muito baixa, baixa, média, alta e muito alta). As classes muito baixa e média são as dominantes.

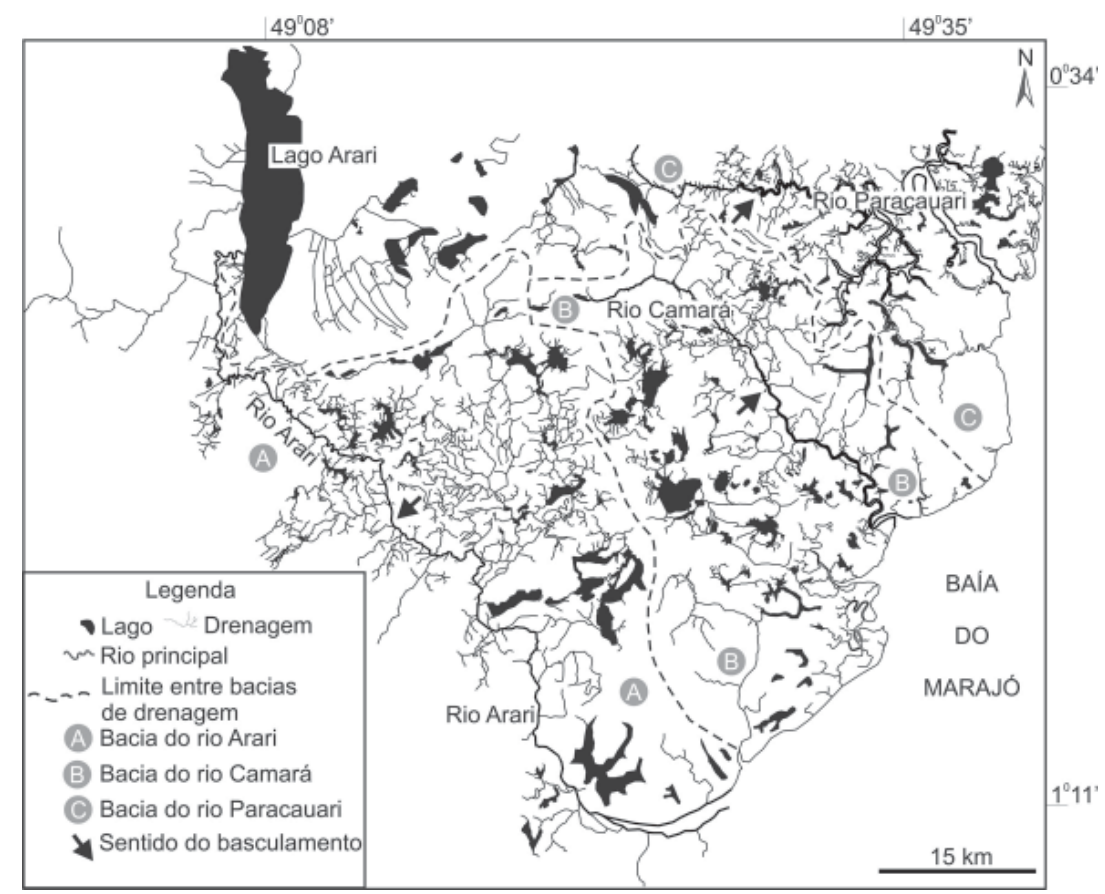

Figura 3 - Mapa das bacias de drenagem estudadas no leste da Ilha do Marajó, derivado da combinação de dados digitais do IBGE/SIVAM com imagem Landsat.

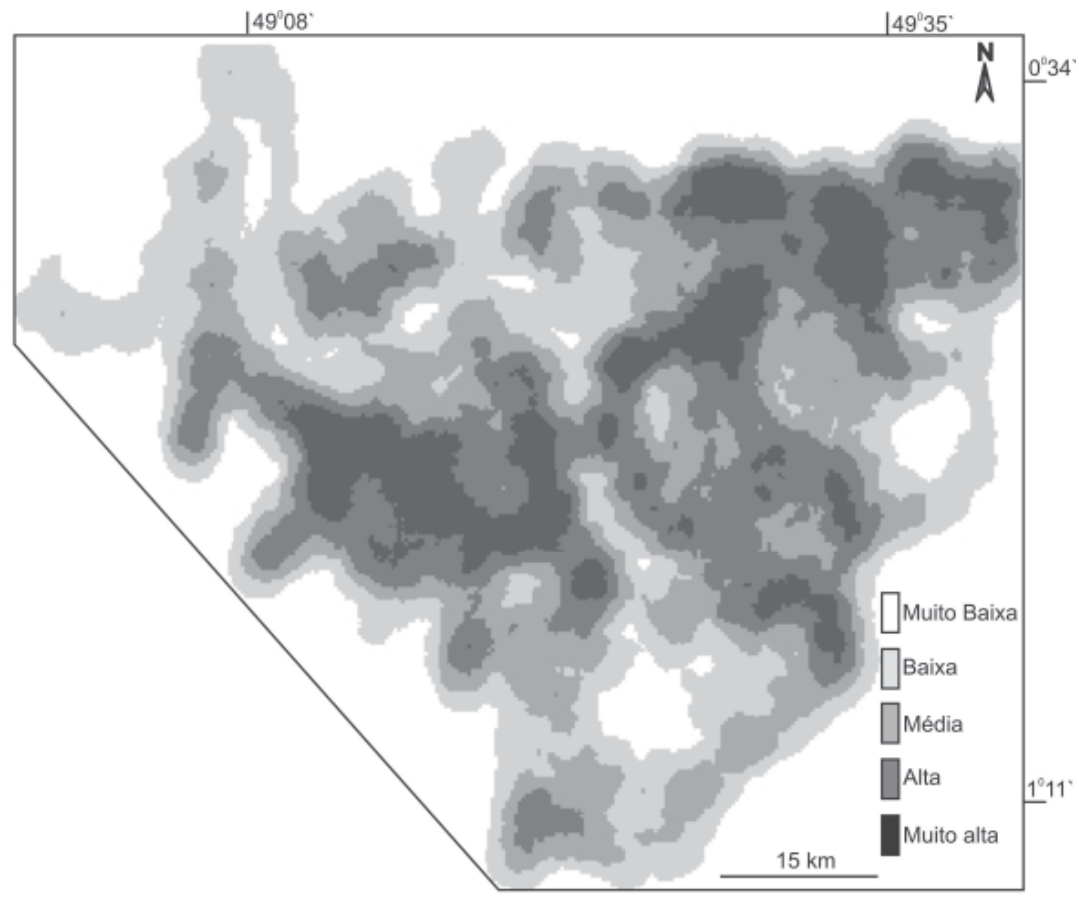

Figura 4 - Mapa de densidade de drenagem. 


\section{Bacia de drenagem do rio Arari (BDRA)}

É a bacia hidrográfica mais extensa da área de estudo, sendo grande parte posicionada em sua porção ocidental, onde totaliza $1.688 \mathrm{~km}^{2}$ (Figura 5). Limitase, a norte com o rio Jenipapacu, a leste com o rio das Almas, a oeste com o rio Anajás Mirim, e a sul com o rio Laranjeiras (Figura 1).

Esta bacia é do tipo exorréica, de densidade média, e com tributários com comprimentos muito maiores em sua margem esquerda relativamente à sua margem direita. Os padrões de drenagem dominantes em sua porção central são dos tipos treliça recurvada e multibacinal. No extremo norte ocorre, de forma isolada, padrão subparalelo e, a sudeste, multibacinal a subtreliça (Figura 5).

Característica marcante na BDRA são anomalias de drenagem (Figura 6). Estas consistem, principalmente, em cursos d'água com ângulo de inflexão de $90^{\circ}$, como por exemplo ao longo do rio Arari, que muda rapidamente de N-S para E-W, formando retângulos abertos geralmente para este (Figura 6A). Esta bacia possui, ainda, como feição marcante, abundância de lagos (Figura 6B), particularmente na porção mediana e à jusante, onde eles são maiores. Em geral, os lagos têm larguras e comprimentos variando de 0,4 a $5 \mathrm{~km}$ e de 0,6 a $10 \mathrm{~km}$, respectivamente. No leste da bacia, os lagos são alongados e, por vezes, ramificados, estando em continuidade física com morfologias relacionadas a paleocanais (ver descrição adiante) (Figura 6C). Adicionalmente, o rio Arari tem, como forte anomalia de drenagem, meandros comprimidos (Figura 6D, E), que se manifestam principalmente no extremo norte e noroeste da bacia. Esses meandros passam rapidamente, à jusante, para canais retilíneos. É interessante observar, ainda, que os padrões de drenagem mudam bruscamente de um tipo a outro, o que é particularmente ilustrado no extremo norte da bacia (Figura 5).

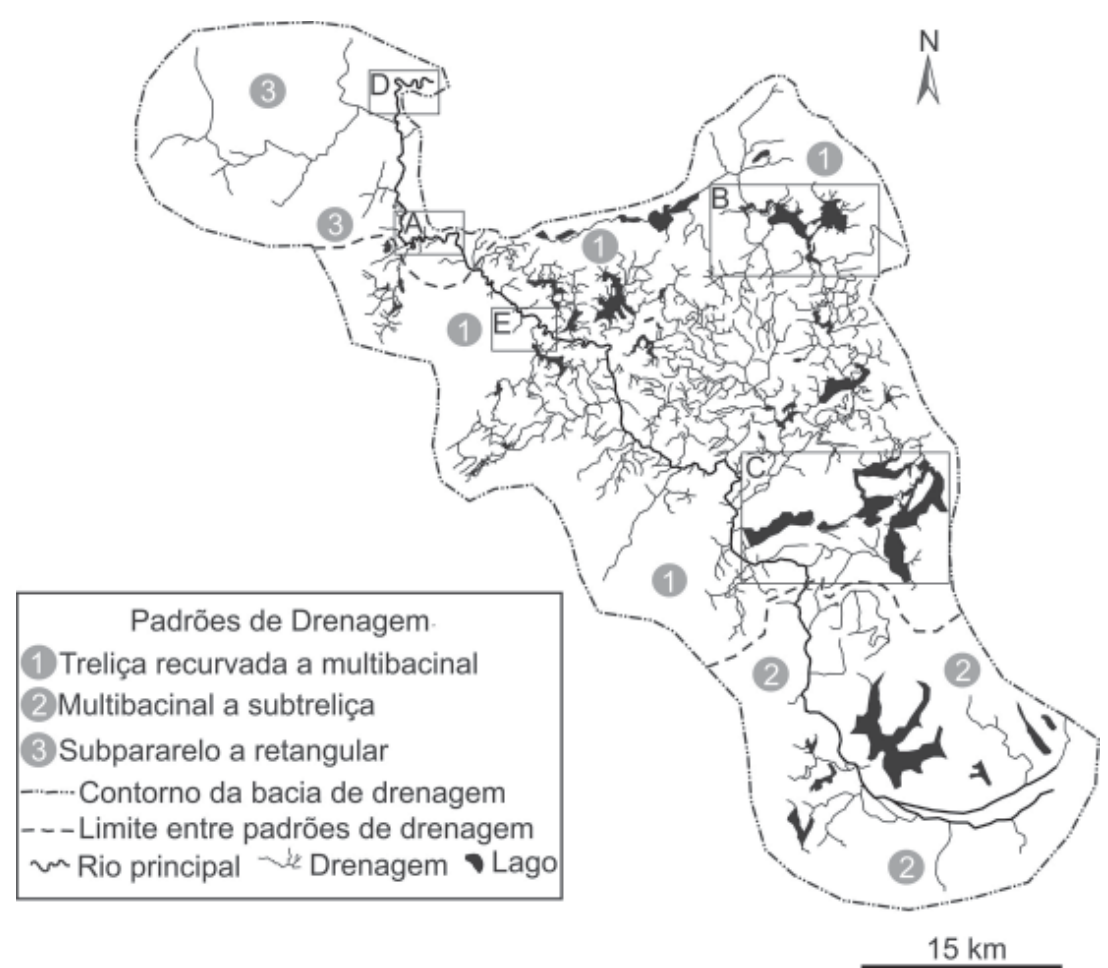

Figura 5 - Bacia de drenagem do rio Arari, com os principais padrões de drenagem. As letras A a D indicam anomalias de drenagem ilustradas na Figura 6. 

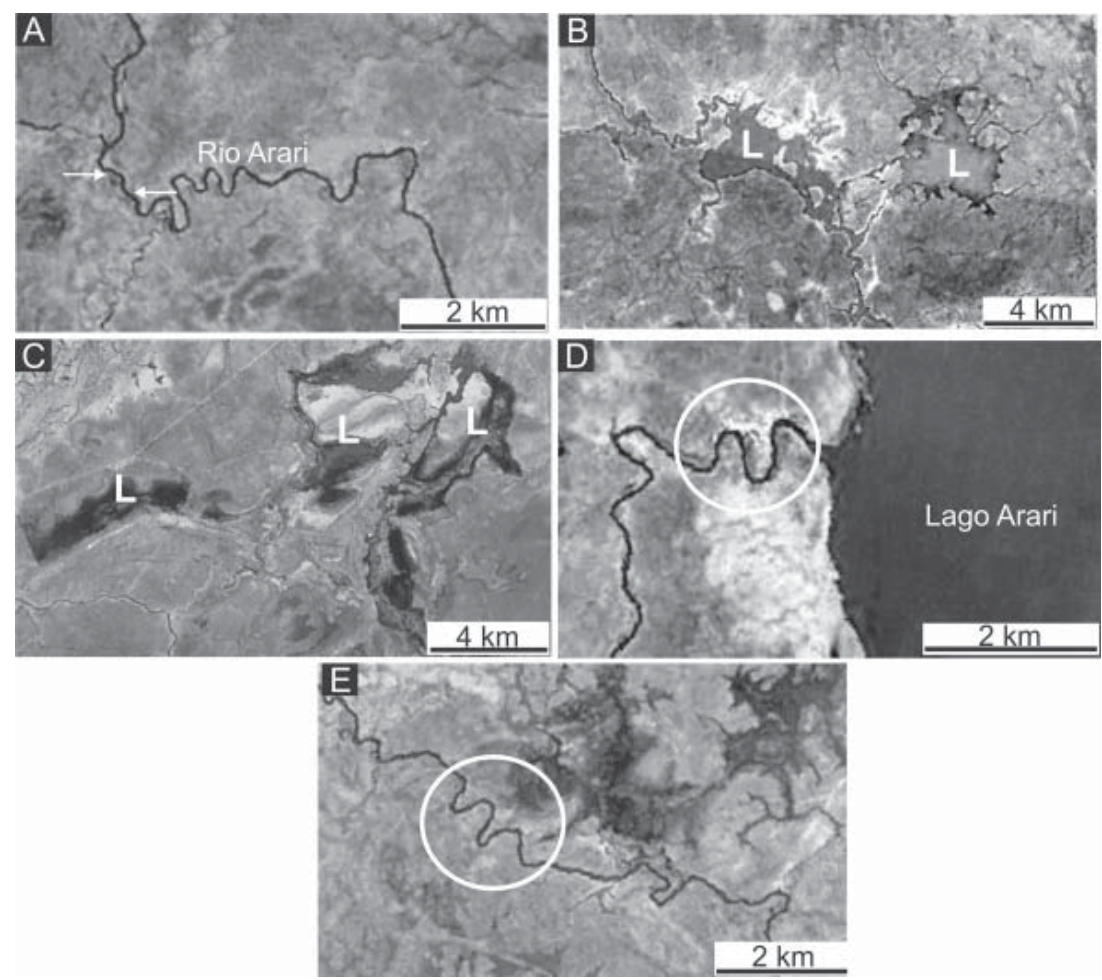

Figura 6 - Imagem Landsat das anomalias de drenagem na BDRA (ver localização na Figura 5). A. Mudanças rápidas no curso do rio Arari, com inflexões de $90^{\circ}$ (seta). B e C. Lagos formados a partir do abandono de canais (L). D e E. Meandros comprimidos (círculos).

\section{Bacia de drenagem do rio Camará (BDRC)}

Esta bacia localiza-se na porção central da área de estudo, onde perfaz um total de $751 \mathrm{~km}^{2}$ (Figura 7). A norte, ela é limitada pelo rio São Miguel e, a sul, pelo rio Abaí (Figura 1). O rio Camará drena de WNW para ENE, tendo forte inflexão para SE em seu médio curso, configurando rápido desvio (quase ortogonal) de drenagem. A bacia é do tipo exorréica, com distribuição de densidade de canais mais variável do que na bacia do rio Arari, oscilando entre baixa e média (Figura 4). Contrariamente à BDRA, os tributários possuem comprimentos maiores na margem direita do rio Camará.

Similarmente à BDRA, esta bacia mostra várias anomalias de drenagem. Por exemplo, a morfologia do rio Camará é dominantemente retilínea, principalmente em seu curso médio, com súbita mudança para meandrante no extremo à jusante. À montante, este rio continua apresentando segmentos retilíneos, porém com trechos de alargamentos bruscos, formando lagos alongados de acordo com a direção do rio, que chegam a atingir até 5 km de extensão e 1,7 km de largura máxima (Figura 8A). Além de lagos, que ocorrem tanto à montante, quanto à jusante desse rio, esta bacia apresenta uma grande incidência de lagos em sua margem direita. Estes têm geometria subalongada a subarredondada, com largura e comprimento variáveis, chegando a 3,5 km e cerca de 8 $\mathrm{km}$, respectivamente. Uma situação interessante ocorre à jusante do rio Camará, onde o canal apresenta meandros localizados e possui, em suas adjacências, lagos que formam segmentos alongados e ramificados em continuidade lateral (Figura 8B).

Não há padrão de drenagem uniforme na BDRC, que é dominada por vários padrões complexos, incluindo-se multibacinal, treliça recurvada e subparalelo. No entanto, a mudança abrupta dos padrões de drenagem de treliça recurvada a mutibacinal e subparalelo no extremo norte, nordeste e sudeste, são indicativos de anomalias de drenagem (Figura 7). 


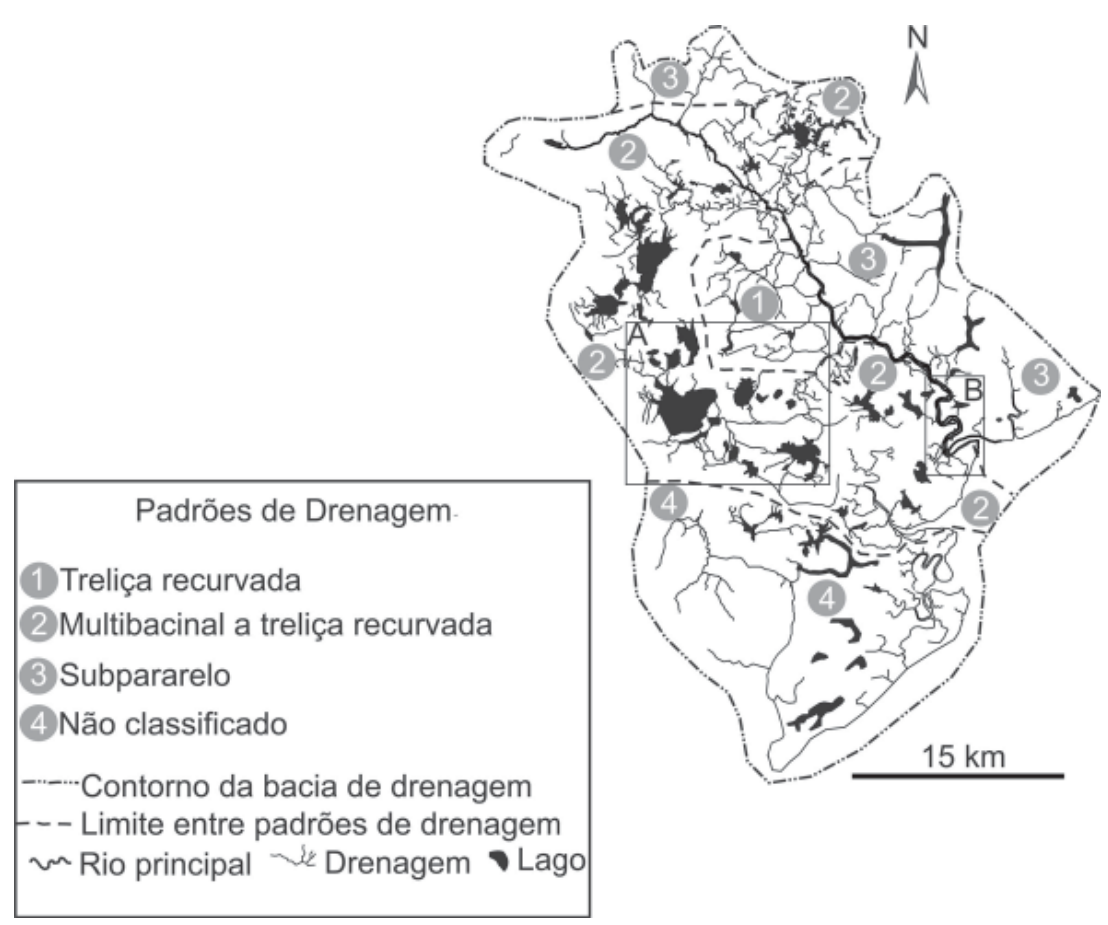

Figura 7 - Bacia de drenagem do rio Camará (ver legenda na Figura 5). As letras A e B indicam anomalias de drenagem ilustradas na Figura 8.
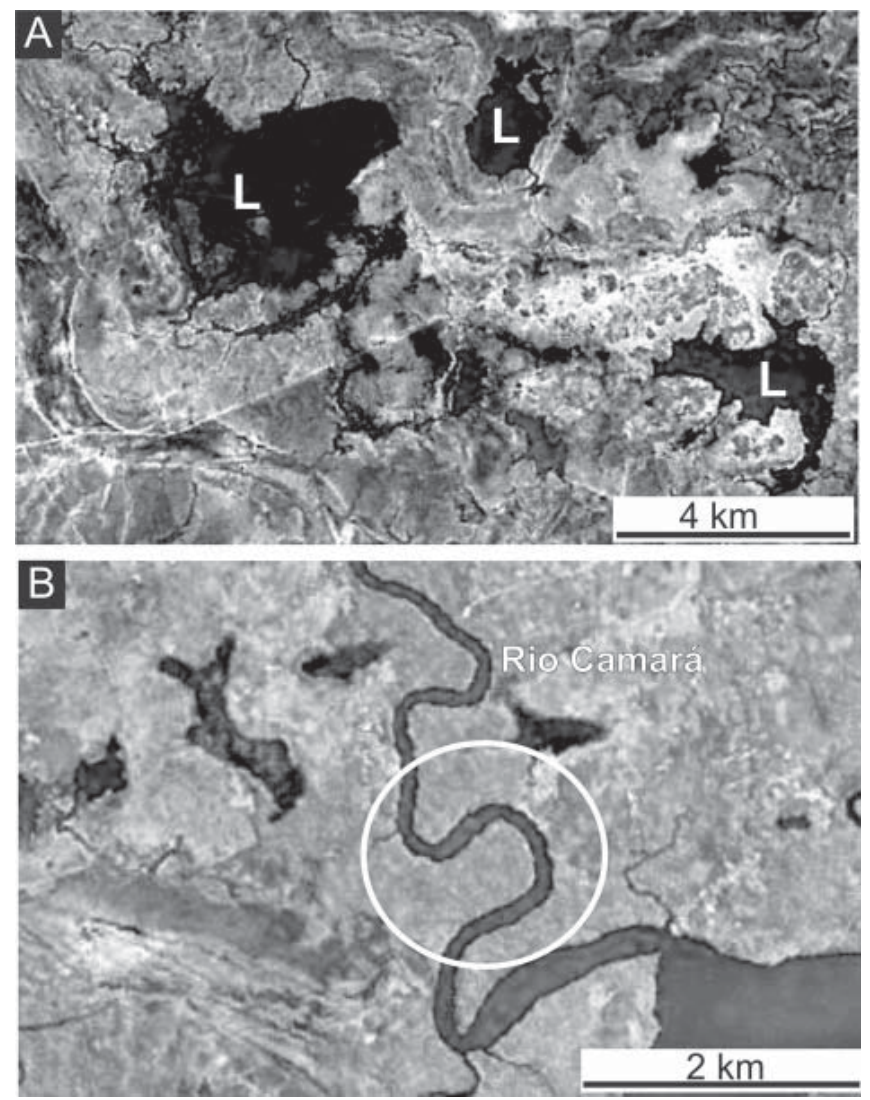

Figura 8 - Imagem Landsat das anomalias de drenagem na BDRC (ver localização na Figura 7). A. Lagos formados a partir do alargamento súbito de canais (L). B. Meandro localizado (círculo). 


\section{Bacia de drenagem do rio Paracauari (BDRP)}

Esta é a menor bacia hidrográfica da área de estudo, estando posicionada em sua parte oriental, onde totaliza $706 \mathrm{~km}^{2}$ (Figura 9). A sudoeste, o rio Paracauari liga-se ao rio Cambu (Figura 1). O rio Paracauari, por ser fortemente sinuoso em suas porções baixa e média, possui desvios moderados de seu curso d'água, sendo que, à montante, flui no sentido E-W, enquanto que, à jusante, sofre alta inflexão (i.e., ângulo de $90^{\circ}$ ), fluindo para N-S e SE.

A bacia é do tipo exorréica, de densidade média. Os tributários são mais longos na margem direita do que na margem esquerda do rio Paracauari, embora não tanto quanto no caso do rio Camará. O padrão de drenagem, em geral, é o treliça recurvada a multibacinal, sendo que, para oeste, ocorre treliça direcional a multibacinal, enquanto que, para o extremo sul, predominam os tipos multibacinal e retangular (Figura 9). Lagos são incomuns e, quando presentes, possuem dimensões similares aos da BDRA (ver Figura 5). Anomalia de drenagem comum consiste em meandros localizados e comprimidos. Este último grada a canais relativamente mais retilíneos à montante da bacia (Figura 10A).

Uma característica marcante da BRP é a natureza fortemente sinuosa do canal principal, em seu baixo curso, enquanto que, para montante, ocorre rápida mudança para canal retilíneo, configurando junções em ângulos retos. Similarmente à BDRC, lagos dispostos em segmentos alongados e ramificados lateralmente contínuos ocorrem, também, nesta bacia (Figura 10B). Tais feições ocorrem, mais especificamente, no extremo leste e sul da bacia, onde os tributários formam padrão anastomosado.

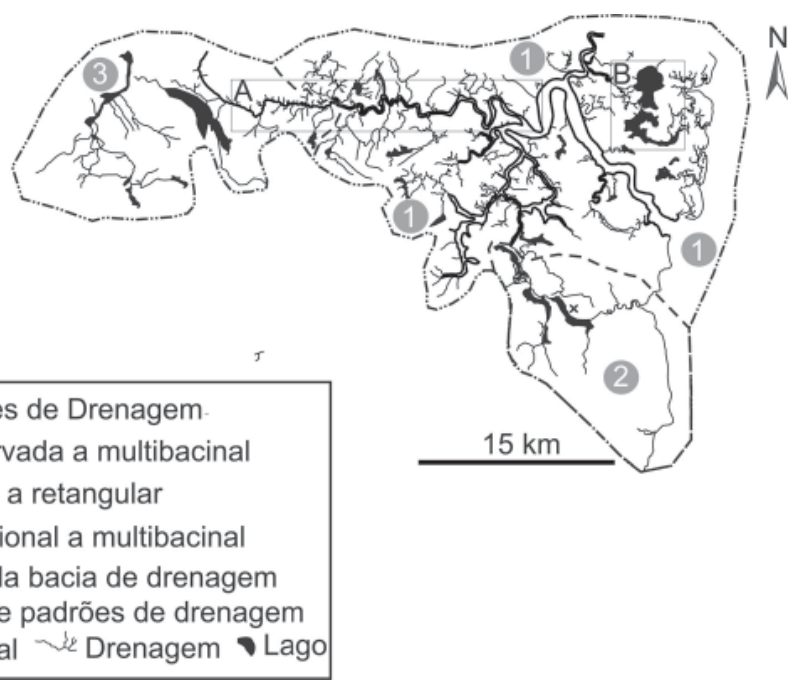

Figura 9 - Bacia de drenagem do rio Paracauari (ver legenda na Figura 5). As letras A e B indicam anomalias de drenagem as quais são observadas na Figura 10.

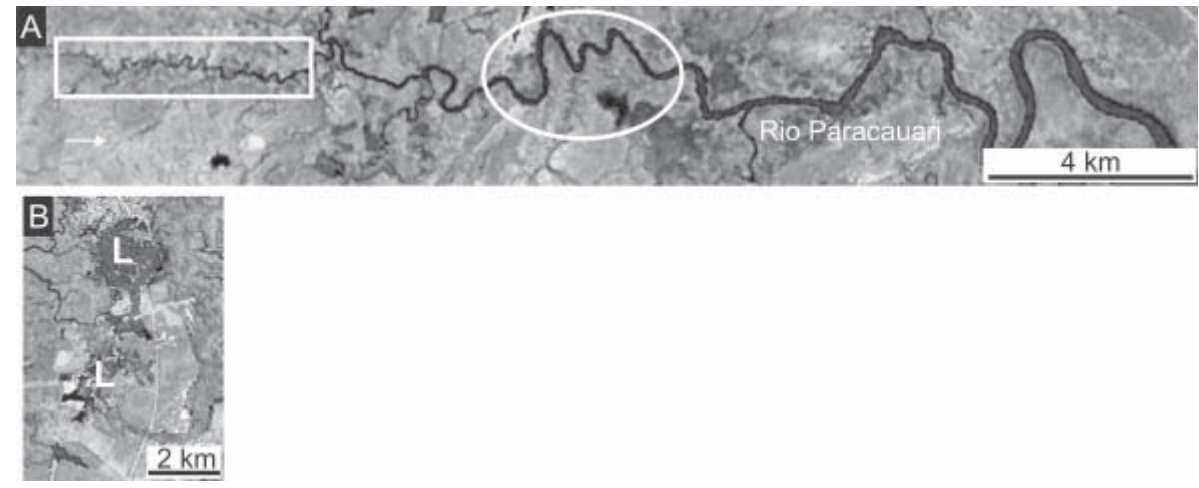

Figura 10 - Imagem Landsat das anomalias de drenagem na BDRP (ver localização na Figura 9). A. Canais fortemente sinuosos (círculo) que mudam para retilíneos (quadrado) (E-W). B. Lagos alongados devido ao rápido alargamento de canais $(L)$. 


\section{Fator de Assimetria}

Com o intuito de complementar a análise de anomalias de drenagem e levantar dados que possibilitem interpretar os lineamentos morfoestruturais, fez-se o cálculo do Fator de Assimetria (FA) considerando-se os rios principais das bacias de drenagem definidas acima. Este fator (Hare \& Gardner 1985; Keller \& Pinter 1996) tem, como fundamento primordial, a medida de assimetria, definida pela relação de canais das margens direita e esquerda do rio principal.

O FA é calculado pela fórmula: $\mathrm{FA}=100$ (Ad/At), onde $\mathrm{FA}=$ fator de assimetria, $\mathrm{Ad}$ =área da margem direita da bacia de drenagem, e At=área total da bacia de drenagem. De forma geral, os dados revelam que as BDRC e BDRP apresentam os maiores valores de assimetria, correspondente a FA = 62 e FA = 71, respectivamente, uma vez que a área à esquerda desses rios é predominantemente inferior à direita. Já a BDRA é a menos assimétrica de todas, como indicado por valor de FA = 42 ( Figura 3). Entretanto, esta baixa simetria é aparente, ocorrendo, mais especificamente, nos cursos baixos e médios do rio Arari, enquanto que as margens no alto curso deste rio mostram-se fortemente assimétricas FA = 84 .

\section{Lineamentos Morfoestruturais}

Em combinação com as anomalias de drenagem e o fator de assimetria, os lineamentos morfoestruturais foram mapeados com o intuito de se levantar dados adicionais que pudessem verificar hipótese de controle tectônico dos sistemas de drenagem da área de estudo (Figura 11). Observa-se que o traçado dos lineamentos morfoestruturais foi estendido além dos limites da área de estudo, a fim de permitir melhor visualização de sua continuidade.

Os diagramas em roseta dos lineamentos morfoestruturais, derivados dos dados de frequências e comprimentos absolutos (Figura 12), mostraram modas principais para NW-SE e NE-SW, e subordinada aproximadamente para E-W. O mapa de densidade de lineamentos (Figura 13) levou ao reconhecimento de dois compartimentos na área de estudo. O compartimento I localiza-se na porção centro-leste, correspondente às margens esquerda e direita dos rios Arari e Paracauari, respectivamente, além do médio e baixo curso do rio Camará. Neste compartimento, ocorre densidade de lineamentos alta, sendo que estes estão orientados, preferencialmente, para NW-SE e NE-SW. O padrão de drenagem característico é o treliça recurvada, direcional, multibacinal e retangular. A ocorrência de paleocanais é baixa neste setor. O compartimento II corresponde ao restante da área, ou seja, margens direita e esquerda dos rios Arari e Paracauari, respectivamente, além do alto curso do rio Camará. Este setor possui densidade de lineamentos muito baixa a média, sendo estes direcionados, em geral, para NE-SW. O padrão de drenagem neste setor é o treliça recurvada, subtreliça, subparalelo e retangular. A ocorrência de paleocanais é alta relativamente ao compartimento I.
Ambos os compartimentos acima descritos são dominados, em superfície, por sedimentos quaternários, mas o compartimento I contém, também, depósitos miocênicos. Além disto, depósitos quaternários são mais delgados no compartimento I do que no II, como indicado pela correlação de perfis litoestratigráficos apresentada em Rossetti (2010).

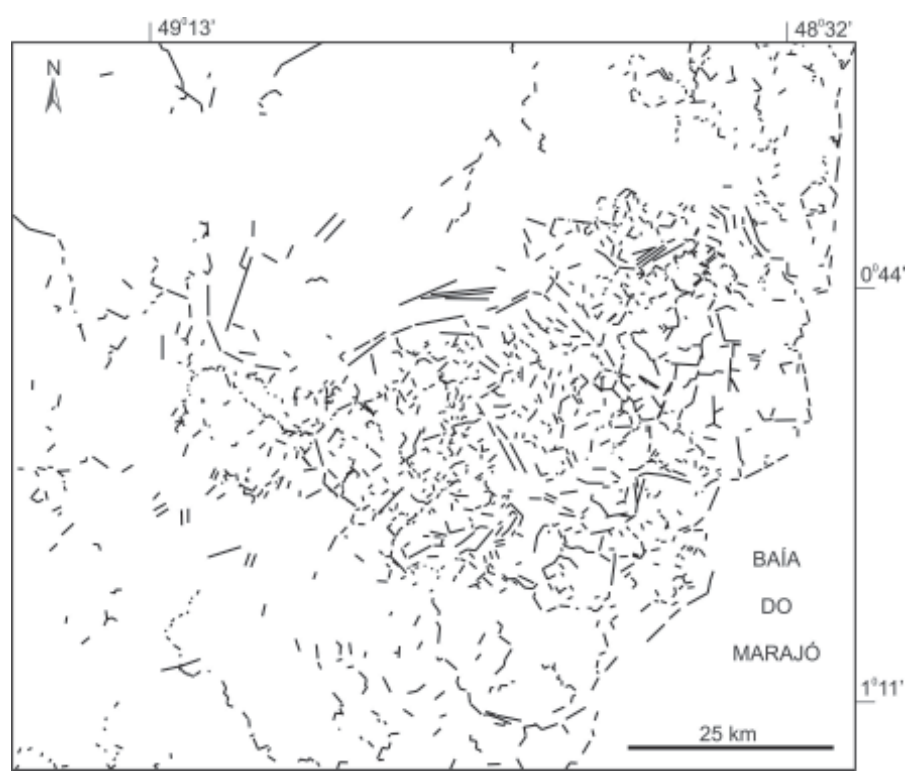

Figura 11 - Lineamentos morfoestruturais derivados da análise da rede de drenagem atual.
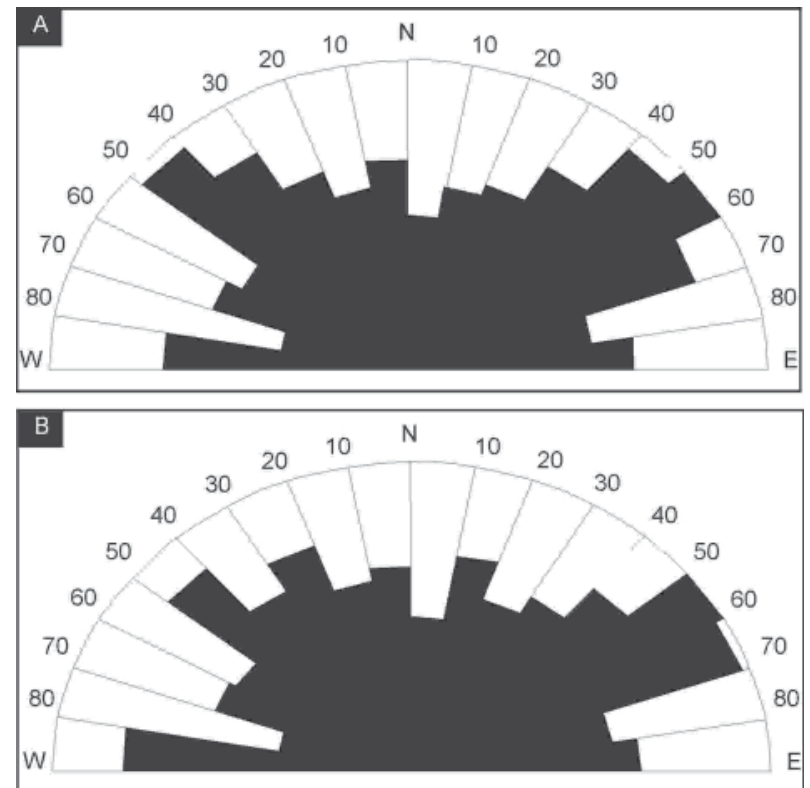

Figura 12 - Diagramas em roseta dos lineamentos morfoestruturais. A. Frequência absoluta ilustrando modas principais para NW e NE. B. Comprimento absoluto ilustrando modas principais para $N W e$ NE. Notar que estas orientações são coincidentes com as obtidas para frequência absoluta, mostradas no diagrama em roseta da Figura 12A. 


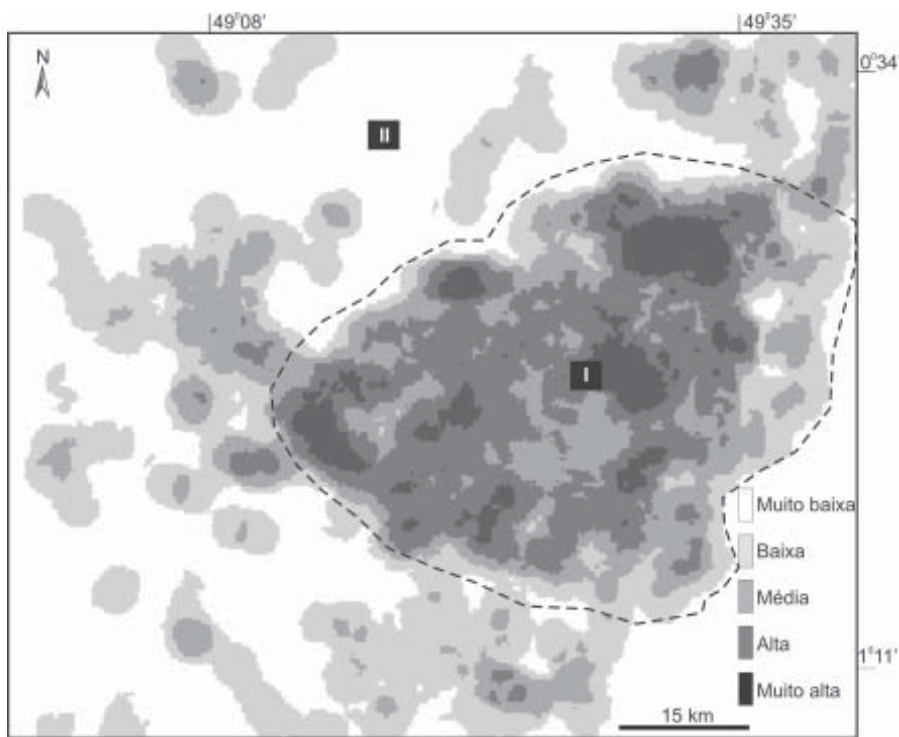

Figura 13 - Mapa de densidade de lineamentos tectônicos. As letras I e II indicam compartimentos morfotectônicos.

\section{Paleocanais}

Feições morfológicas relacionadas a paleocanais são presentes na área de estudo, embora em volume inferior ao verificado em outras áreas da Ilha do Marajó, como relatado em trabalhos prévios (Rossetti et al. 2007; Rossetti \& Góes 2008; Rossetti et al. 2008). Estes são, em geral, contínuos, mas também ocorrem paleocanais representados por segmentos isolados, cuja continuidade lateral pode ser facilmente reconstituída dada sua distribuição espacial (Figura 14).

Os paleocanais possuem formas alongadas a levemente sinuosas e localmente meandrantes. Seus comprimentos variam entre 2,5 e $50 \mathrm{~km}$ e as larguras entre 0,5 e aproximadamente $5 \mathrm{~km}$. Anomalias de drenagem também podem ser reconhecidas no sistema de paleodrenagem, o que é principalmente indicada por frequentes mudanças bruscas na direção dos paleocanais, configurando desvios em ângulo reto (ver círculos na Figura 14), além de meandros isolados e comprimidos.

A determinação do sentido do paleofluxo é problemática, uma vez que os paleocanais não necessariamente fazem parte de um mesmo sistema de drenagem, podendo registrar canais que migraram com o tempo, resultando em um sistema complexo de morfologias sobrepostas.

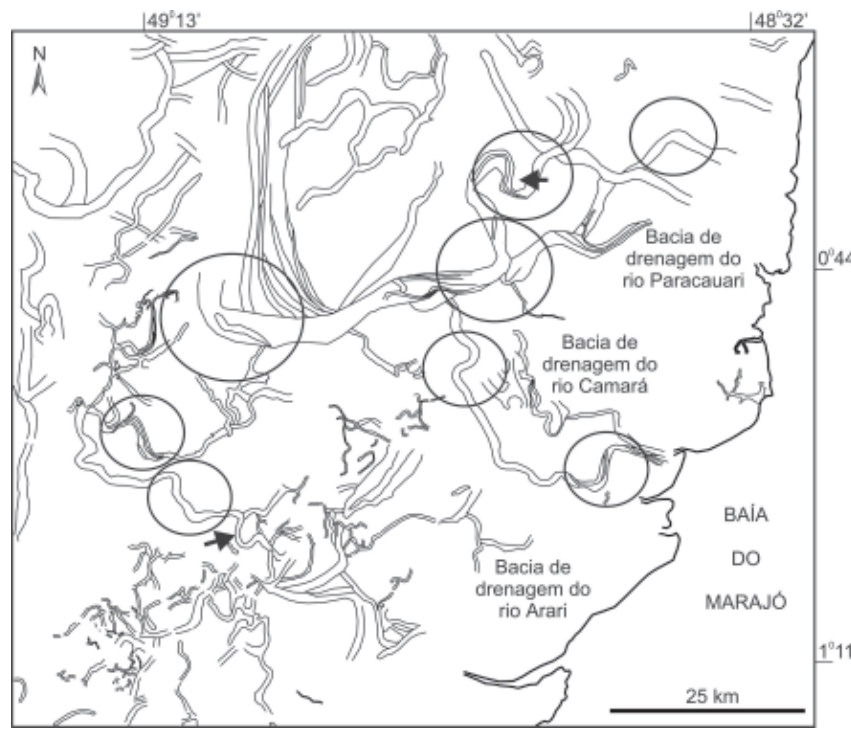

Figura 14 - Mapa de paleocanais derivados da análise visual de imagem Landsat. Círculos indicam locais onde ocorrem rápidos desvios de direção dos paleocanais, configurando ângulos retos. Setas indicam meandros isolados e comprimidos.

\section{Discussão}

O desenvolvimento de bacias de drenagem mostra, em geral, influências locais e regionais impostas por vários fatores, principalmente litológicos, topográficos, tectônicos e climáticos. Dentre estes, o fator tectônico apresenta-se como o mais provável no controle dos sistemas de drenagem da área de estudo. Esta interpretação é sugerida por uma série de características, como será discutido abaixo.

Primeiro, padrão de drenagem em treliça, amplamente dominante na área de estudo, é comum em associação a feições estruturais (e.g., Holmes 1965; Howard 1967; Cotton 1968; Cristofoletti 1981; Hare \& Gardner 1985; Doornkamp 1986; Summerfield 1991).

Segundo, a associação dos sistemas de drenagem com fatores tectônicos é consistente com variações rápidas de padrão dentro de uma mesma bacia. Mudanças abruptas na orientação dos cursos d'água, frequentemente formando ângulos de $90^{\circ}$ e configurando padrões de drenagem retangular, como verificado, por exemplo, nos rios Arari e Camará, são consistentes com esta proposição. Adicionalmente, as inúmeras anomalias de drenagem, incluindo meandros localizados e comprimidos, canais meandrantes que se tornam bruscamente retilíneos, áreas com alto volume de lagos que configuram drenagem do tipo multibacinal, além da presença de drenagem subparalela, são fortemente sugestivas de controle tectônico na área de estudo. 
Terceiro, o forte controle tectônico na área de estudo é, ainda, sugerido pelo Fator de Assimetria (FA) das bacias de drenagem, já que este fator pode revelar terrenos basculados. Valores muito superiores ou muito inferiores a 50 sugerem basculamentos da margem direita e esquerda do rio, respectivamente, enquanto que valores próximos a 50 denunciam estabilidade tectônica (Keller \& Pinter 1996; Marques Neto \& Viadana 2006). Portanto, os valores de FA $=62$ e FA $=71$ para as BDRC e BDRP, respectivamente, são compatíveis com basculamentos da margem direita do rio. $\mathrm{O}$ valor de $\mathrm{FA}=42$ para a BDRA mostra que esta área esteve relativamente mais estável. Entretanto, se considerado apenas as margens do alto curso do rio Arari, onde o $\mathrm{FA}=84$ pode-se concluir que este setor da bacia esteve, também, sob forte influência tectônica, com basculamento para a direita.

A variação de valores de FA ao longo de uma bacia de drenagem pode registrar heterogeneidades na distribuição de esforços tectônicos (Holmes 1965; Howard 1967; Cristofoletti 1981). Na área de estudo, esta situação é adicionalmente sugerida pela mudança de padrões e anomalias de drenagem em áreas mostrando FA variável. Portanto, conclui-se que, quando combinados às anomalias de drenagem descritas neste trabalho, os valores de FA das três bacias de drenagem estudadas desenvolveram-se, muito provavelmente, sob forte controle tectônico.

As direções preferenciais dos lineamentos morfoestruturais para NE-SW e NW-SE são compatíveis com as orientações principais de estruturas tectônicas registradas na Ilha da Marajó. A ilha permaneceu tectonicamente instável durante o Neocretáceo, quando falhas reversas NE-SW, falhas normais NE-SW, e falhas transcorrentes dextrais ENE-WSW e NE-SW foram geradas (Villegas 1994; Costa \& Hasui 1997; Costa et al. 2002; Bemerguy 2002). Estas estruturas foram reativadas posteriormente, inclusive durante o Holoceno, o que resultou na geração de espaço para acomodar novas sucessões sedimentares (p.e., Rossetti et al. 2008b; Mantelli 2009). O registro de terremotos com intensidade moderada (magnitude 4,8) na ilha revela que estas falhas podem estar ainda em atividade (Miotto 1993).

Considerando-se a proposta de controle tectônico na área de estudo, a densidade maior de lineamentos orientados para NW-SE e NE-SW sugere que o compartimento morfoestrutural I pode incorporar terrenos geologicamente mais antigos que o compartimento II próximos à superfície. Esta interpretação é sustentada pelo fato de ambos os compartimentos apresentarem sedimentos quaternários, mas somente o compartimento I conter depósitos miocênicos expostos na superfície.

Uma possibilidade de interpretação é que, por conter depósitos mais antigos próximo à superfície, o compartimento I registre a superposição de diferentes eventos tec- tônicos, enquanto que os lineamentos do compartimento II registrariam apenas estruturas formadas mais recentemente. Esta interpretação é, ainda, condizente com o fato de haver maior concentração de lineamentos morfoestruturais NW-SE e NE-SW no compartimento I, enquanto o compartimento II apresenta predomínio de lineamentos NE-SW. Isto porque a reativação de falhas tectônicas de direção NW-SE é anterior ao desenvolvimento de falhas NE-SW no leste da Ilha do Marajó (Rossetti et al. 2007). Portanto, por conter maior volume de sedimentos na superfície, o compartimento II registraria somente este último evento de reativação de falha. Entretanto, não se pode descartar a possibilidade de que os eventos tectônicos teriam ocorrido de forma diferencial, tendo afetado mais fortemente, o compartimento I.

Várias hipóteses podem ser levantadas para explicar o abandono de paleocanais no leste da Ilha do Marajó: (a) diminuição no nível do lençol freático devido à maior aridez durante fases glaciais; (b) oscilação do lençol freático devido à queda eustática; e (c) ação tectônica.

A primeira hipótese não parece contundente com reconstituições paleoclimáticas na Amazônia, onde se registra aumento progressivo de umidade no Holoceno (Baker et al. 2001; Sifeddine et al. 2001). Entretanto, existe registro de que os canais do leste do Marajó foram referencialmente abandonados nesse intervalo de tempo (Rossetti et al. 2008a). Portanto, contrariamente ao que ocorreu, este aumento de umidade deveria ter contribuído para a reativação e ampliação dos canais, e não levado ao seu abandono.

A segunda hipótese também parece não ser confirmada, já que o nível eustático teve comportamento dominante de elevação durante o Holoceno (Behling \& Costa 2000; Behling 2001; Souza Filho \& Paradella 2003; Cohen et al. 2004 e 2005a, b; Vedel et al. 2006). Portanto, ação tectônica parece ser mais consistente, principalmente quando se leva em consideração o contexto estrutural proposto para a Ilha do Marajó (Rossetti \& Valeriano 2007; Rossetti et al. 2008a). De acordo com estes autores, o paleoestuário Arari teria sido abandonado no leste da ilha quando esta se destacou do continente, processo este que resultou na abertura da Baía do Marajó.

O mais provável, então, é que a abertura dessa baía interrompeu o fluxo fluvial derivado de áreas continentais para o interior da ilha, o que teria causado modificação nos sistemas de drenagens, e também o abandono do paleoestuário Arari. À medida que este processo ocorreu, as bacias de drenagem passaram a ser capturadas e desviadas para sudeste, fluindo em direção àquela baía. A presença de anomalias de drenagem, representada por frequentes desvios de curso em ângulo reto e meandros isolados e comprimidos é consiste com a interpretação de que a drenagem pretérita neste setor da ilha também esteve sob controle tectônico. 


\section{Conclusão}

Os resultados da análise morfoestrutural dos sistemas de drenagem feitos com apoio de dados de sensoriamento remoto permite concluir que o leste da ilha do Marajó apresenta fortes evidências de feições tectônicas afetando a sedimentação quaternária.

Isto é revelado pelas seguintes características, presente em todas as três bacias de drenagem analisadas: coincidência na orientação dos lineamentos morfoestruturais com a orientação geral de falhas tectônicas registradas na Amazônia oriental; predomínio de padrões de drenagem variáveis, principalmente incluindo treliça, retangular e multibacinal; abundância de anomalias de drenagem, incluindo desvios de drenagem em ângulos retos, canais retilíneos e meandros comprimidos e localizados; e predomínio de bacias com forte assimetria. Além disto, a paleodrenagem preservada na paisagem atual também mostra evidências de controle tectônico.

Estudos futuros são ainda necessários para a melhor caracterização de falhas na área estudada. Entretanto, a análise morfoestrutural aqui apresentada permitiu a identificação de áreas com forte anomalia de drenagem, as quais devem ser prioritariamente investigadas como de maior potencial para a caracterização da falhas tectônicas em subsuperfície utilizando-se, por exemplo, métodos geofísicos.

\section{Agradecimento}

Este trabalho foi financiado pela FAPESP (Projeto\#004/15518-6).

\section{Referências Bibliográficas}

ALMEIDA-FILHO, R.; MIRANDA, F. P. Mega capture of the Rio Negro and formation of the Anavilhanas Archipelago, Central Amazônia, Brazil: evidences in an SRTM digital elevation model. Remote Sensing of Environment, v. 110, p. 387-392, 2007.

ARAI, M.; UESUGUI, N.; ROSSETTI, D. F.; GÓES, A. M. Considerações sobre a idade do Grupo Barreiras no nordeste do Estado do Pará. In: CONGRESSO BRASILEIRO DE GEOLOGIA, 35, 1988, Belém. Anais....Belém: Sociedade Brasileira de Geologia, 1988. v. 2, p. 738-752.

BAKER, P. A.; SELTZER, G. O.; FRITZ, S. C., DUNBAR, R. B.; GROVE, M. J.; TAPIA, P. M.; CROSS, S. L.; ROWE, H. D.; BRODA, J. P. The history of South American tropical precipitation for the past 25,000 years. Science, v. 291, p. $640-$ 643, 2001.

BEHLING, H. Late Quaternary environmental changes in the Lagoa da Curuça region (eastern Amazonia, Brazil) and evidence of Podocarpus in the Amazon lowland. Vegetation History and Archaeobotany, v. 10, p. 175-183, 2011.
BEHLING, H.; COSTA, M. L. Holocene environmental changes from the Rio Curuá record in the Caxiuanã region, eastern Amazon Basin. Quaternary Research, v. 53, p. 369-377, 2000.

BEMERGUY, R. L. Morfotectônica e evolução paleogeográfica da região da calha do Rio Amazonas. 1997. 200 f. Tese (Doutorado em Geologia) - Instituto de Geociências, Universidade Federal do Pará, Belém. 1997.

BEMERGUY, R. L. Estudo Sedimentológico dos Paleocanais da Região do Rio Paracauari, Ilha do Marajó - Estado do Pará. 1981. 95 f. Dissertação (Mestrado em Geologia) - Instituto de Geociências, Universidade Federal do Pará, Belém. 1981.

BEMERGUY, R. L.; COSTA, J. B. S.; HASUI, Y.; BORGES, M. S.; SOARES JR., A.V. Structural geomorphology of the Brazilian Amazon region. In: KLEIN, E. L.; VASQUE, M.L.; ROSA, C. L. T. (Eds.). Contribuição à geologia da Amazônia. Belém: Sociedade Brasileira de Geologia, Núcleo Norte, 2002. p. $245-258$.

BERGER, Z. Satellite hydrocarbon exploration: interpretation and integration techniques. Berlin: Springer-Verlag-Heidelberg, 1994. $319 \mathrm{p}$.

BEZERRA, P. E. L. Compartimentação morfotectônica do interflúvio Solimões-Negro. 2003. 100 f. Tese (Doutorado em Geologia) - Instituto de Geociências, Universidade Federal do Pará, Belém. 2003.

BLOOM, A. L. Geomorphology: a systematic analysis of late Cenozoic landforms. Englewood Cliffs: Prentice Hall, 1991. $532 \mathrm{p}$.

CHRISTOFOLETTI, A. Geomorfologia fluvial. São Paulo: Edgard Blücher, 1981. $313 \mathrm{p}$.

COHEN, M. C. L.; LARA, R. J.; SZLAFSZTEIN, C. F.; DITTMAR, T. Mangrove Inundation and Nutrient Dynamics under a GIS perspective. Wetlands Ecology and Management, v. 12, p. 81-86, 2004.

COHEN, M. C. L.; BEHLING, H.; LARA, R. J. Amazonian mangrove dynamics during the last millennium: The relative sea-level and the Little Ice Age. Review of Palaeobotany and Palynology, v. 136, p. 93-108, 2005a.

COHEN, M. C. L.; SOUZA FILHO, P. W. M.; LARA, R. J.; BEHLING, H.; ANGULO, R. J. A model of Holocene mangrove development and relative sea-level changes on the Bragança Peninsula (Northern Brazil). Wetlands Ecology and Management, v. 13, p. 433-443, 2005b.

CORREA, P. R. S.; PERES, R. N.; VIEIRA, L. S. Solos. In: Brasil. PROJETO RADAM (Eds.). Folha Belém SA-22. Rio de Janeiro: DNPM (Levantamento de Recursos Naturais), 1974. v. 5, p. 1-53.

COSTA, J. B. S. \& HASUI, Y. Evolução geológica da Amazônia. In: COSTA, M. L.; ANGÉLICA R. S. (Eds.). Contribuições à geologia da Amazônia. Belém: Sociedade Brasileira de Geologia, 1997. p. 15-19. 
COSTA, J. B. S; HASUI, Y. BERMERGUY, R. L. SOARES JR., A.V.; VILLEGAS, J. M. C. Tectonics and paleogeography of the Marajó Basin, northern Brazil. Anais da Academia Brasileira de Ciências, v. 74, p. 519-531, 2002.

COSTA, J. B. S.; BEMERGUY, R. L.; HASUI, Y.; BORGES, M. S. Tectonics and paleogeography along the Amazon River. Journal South American Earth Sciences, v. 14, p. 335-347, 2001.

COTTON, A. Geomorphology. London: Witcombe \& Tombs Ltd., 1968. 187 p.

DEFFONTAINES, B.; CHOROWICZ, J. Principles of drainage basin analysis from multisource data: application to the strutural analysis of the Zaire Basin. Tectonophysics, v. 194, p. 237-263, 1991.

DELCAILLAU, B.; CAROZZA, J.M.; LAVILLE, E. Recent fold growth an drainage development: the Janauri and Chandigarh anticlines in the Siwalik foothills, northwest India. Geomorphology, v. 76, p. 241-256, 2006.

DEPARTAMENTO NACIONAL DE METEOROLOGIA DNMET. Normas climatológicas. Brasília, DF, 1992, 84 p.

DOORNKAMP, J.C. Geomorphological approaches to the study of Neotectonics. Journal of the Geological Society of London, v. 143, p. 335-342, 1986.

EL HAMDOUNI, R.; IRIGARAY, C.; FERNÁNDEZ, T.; CHACÓN, J.; KELLER, E. A. Assessment of relative active tectonics, southwest border of the Sierra Nevada (southern Spain). Geomorphology, v. 96, 150-173, 2008.

GARCÍA-TORTOSA, F. J.; ALFARO, P.; GALINDOZALDÍVAR, J.; GIBERT, L.; LÓPEZ-GARRIDO, A. C.; SANZ DE GALDEANO, C.; UREÑA, M. Geomorphologic evidence of the active Baza Fault (Betic Cordillera, South Spain). Geomorphology, v. 97, 374-391, p. 2008.

GÓES, A. M.; ROSSETTI, D. F.; NOGUEIRA, A. C. R.; TOLEDO, P. M. Modelo deposicional preliminar da Formação Pirabas no nordeste do Estado do Pará. Boletim do Museu Paraense Emílio Goeldi (Série Ciências da Terra 2), v. 2, p. 3-15, 1990.

HARE, P.W. \& GARDNER, I.W. Geomorphic indicators of vertical neotectonism along converging plate margins. Nicoya Peninsula, Costa Rica. In: MORISAWA, M.; HACK, J. T. (Eds.). Tectonic geomorphology. Boston: Proceedings 15. Annual Binghamton Geomorphology Symposium. Allen and Unwin, 1985. p. 123-134.

HOLMES, A. Principles of physical geology. 2. ed. London: Thomas Nelson. 1965. 1288 p.

HOWARD, A.D. Drainage analysis in geologic interpretation: a summation. American Association of Petroleum Geologists Bulletin, v. 51, p. 2246-2259, 1967.

INSTITUTO DE DESENVOLVIMENTO ECONÔMICO SOCIAL DO ESTADO DO PARÁ - IDESP. Estudos integrados da Ilha do Marajó. Belém, PA, 1974, 333 p.
KEHEW, A. E. Geology for engineers and environmental scientists. New Jersey: Prentice Hall, 1995. 574 p.

KELLER, E. A.; PINTER, N. Active tectonics: earthquakes, uplift, and landscape. New Jersey: Prentice-Hall, 1996. 338 p.

LATRUBESSE, E. M.; RANCY, A. The Late Quaternary of the Upper Juruá River, southwestern Amazonia, Brazil: geology and vertebrate paleontology. Quaternary of South America and Antarctic Península, v. 11, p. 27-46, 1998.

MALIK, J. N.; MOHANTY, C. Active tectonic influence on the evolution of drainage and landscape: geomorphic signatures from frontal and hinterland areas along the northwewstern Himalaya, India. Journal of Asian Earth Sciences, v. 29, p. 604-618, 2007.

MANTELLI, L. R.; ROSSETTI, D. F. Significado tectônico de lineamentos de drenagem no sudoeste da ilha do Marajó. Revista Brasileira de Geociências, v. 39, p. 1-13, 2009.

MIOTTO, J.A. Sismicidade e zonas sismogênicas do Brasil. 1993. 343 f. Tese (Doutorado em Geologia) - Instituto de Geociências e Ciências Exatas, Universidade Estadual Paulista, Rio Claro. 1993.

PEDRERA, A.; PÉRE-PEÑA, J.V.; GALINDO-ZALDÍVAR, J.; AZAÑÓN, J.M.; AZOR, A. Testing the sensitivity of geomorphic índices in areas of low-rate active folding (eastern Betic Cordillera, Spain). Geomorphology, v. 105, p. 218-231, 2009.

PETERS, G.; VAN BALEN, R.T. Tectonic geomorphology of the northern Upper Rhine Graben, Germany. Global and Planetary Change, v. 58, p. 310-334, 2007.

REZENDE, W.; FERRADAES, J. Integração geológica regional da bacia sedimentar da Foz do Amazonas. Belém: Petrobras/ Departamento de Exploração. Relatório Interno, 27 p. 1971.

ROSSETTI, D. F. Influence of low amplitude/high frequency relative sea-level changes in a wave-dominated estuary (Miocene), São Luís Basin, northern Brazil. Sedimentary Geology, v. 133, p. 295-324, 2000.

ROSSETTI, D. F. Late Cenozoic sedimentary evolution in northeastern Pará, Brazil, within the context of sea level changes. Journal of South American Earth Sciences, v. 14, p. 77-89, 2001.

ROSSETTI, D. F. Tectonic control on the stratigraphy framework of Late Pleistocene and Holocene deposits in Marajó Island, State of Pará, eastern Amazonia. Anais da Academia Brasileira de Ciências, v. 82, p. 439-450, 2010.

ROSSETTI, D. F.; GÓES, A.M. Late quaternary drainage dynamics in Northern Brazil. based on the study of a large paleochannel from southwestern Marajó Island. Anais da Academia Brasileira de Ciências, v. 80, p. 1-15, 2008.

ROSSETTI, D. F.; VALERIANO, M. M. Evolution of the lowest amazon basin modeled from the integration of geological and SRTM topographic data. Catena, v. 70, p. 253-265, 2007. 
ROSSETTI, D. F. \& TOLEDO, P.M. Biodiversity from a historical geology perspective: a cause study from Marajó Island, lower Amazon. Geobiology, v. 4, p. 215-223, 2006.

ROSSETTI, D. F.; GÓES, A. M.; VALERIANO, M. M.; THALLÊS, M. Paleodrainage in Marajó Island (northern Brazil) and its relation to Holocene relative sea-level dynamics. Holocene, v. 18, p. 923-934, 2008a.

ROSSETTI, D. F; GÓES, A. M.; VALERIANO, M. M; MIRANDA, M. C. C. Quaternary tectonics in a passive margin: Marajó Island, northern Brazil. Journal of Quaternary Science, v. 23, p. 121-135, 2008b.

ROSSETTI, D. F.; VALERIANO, M. M.; THALLÊS, M. An abandoned estuary within Marajó Island: implications for late quaternary paleogeography of northern Brazil. Estuaries and Coasts, v. 30, p. 813-826, 2007.

ROSSETTI, D. F., TRUCKENBRODT, W.; GÓES, A. M. Estudo paleoambiental e estratigráfico dos Sedimentos Barreiras e PósBarreiras na região Bragantina, nordeste do Pará. Bol. Museu Paraense Emílio Goeldi (Série Ciências da Terra 1), v. 1, p. 25-28, 1989.

SALVI, S. Analysis and interpretation of Landsat synthetic stereo pair for the detection of active fault zone in the Abruzzi region (Central Italy). Remote Sensing of Environment, v. 53, p. 153-163, 1995.

SIFEDDINE, A.; MARINT, L.; TURCQ, B.; VOLKMERRIBEIRO, C.; SOUBIÈS, F.; CORDEIRO, R. C.; SUGUIO, $K$. Variations of the Amazonian rainforest environment: a sedimentological record covering 30,000 years. Palaeogeography, Palaeoclimatology, Palaeoecology, v. 168, p. 221-235, 2001.

SHTOBER-ZISU, N.; GREENBAUM, N.; INBAR, M.; FLEXER, A. Morphometric and geomorphic approaches for assessment of tectonic activity, Dead Sea Rift (Israel). Geomorphology, v. 102, p. 93-104, 2008.

SINGH, V.; TANDON, S. K. The Pinjaur dun (intermontane longitudinal valley) and associated active mountain fronts, NW Himalaya: tectonic geomorphology and morphotectonic evolution. Geomorphology, v. 102, p. 376-394, 2008.
SOUZA FILHO, P. W. M. Tectonic control on the coastal zone geomorphology of the northeastern Pará State. Revista Brasileira de Geociências, v. 30, p. 523-526, 2000.

SOUZA FILHO, P. W. M.; EL ROBRINI, M. Coastal zone geomorphology of the Bragança Area, Northeast of Amazon Region, Brazil. Revista Brasileira de Geociências, v. 30, p. 518-522, 2000.

SOUZA FILHO, P. W. M.; PARADELLA, W. R. Use of synthetic aperture radar for recognition of coastal geomorphological features, land-use assessment and shoreline changes in Bragança coast, Pará, northern Brazil. Anais da Academia Brasileira de Ciências, v. 75, p. 341-356, 2003.

SUMMERFIELD, M. A. Global Geomorphology. New York, Jonh Wiley \& Sons, 1991. 537 p.

TEIXEIRA NETO, J. F.; SOUZA FILHO, A. P. S.; MARQUES, J. R. F.; CAMARÃO, A. P.; TEIXEIRA, R.N. G. Introdução e avaliação de forrageiras na Ilha de Marajó-Pará. Belém (PA). Embrapa. Boletim de Pesquisa, v. 122, p. 1-10, 1991.

TSODOULOS, I. M.; KOUKOUVELAS, I. K.; PAVLIDES, S. Tectonic geomorphology of the easternmost extension of the Gulf of Corinth (Beotia, Central Greece). Tectonophysics, v. 453, p. 211-232, 2008.

VEDEL, V.; BEHLING, H. COHEN, M. C. L.; LARA, R.J. Holocene mangrove dynsamics and sea-level changes in northern Brazil, inferences from the Taperebal core in northeastern Pará State. Vegetation History And Archaeobotany, v. 15, p 115-123, 2006.

VILLEGAS, J.M. Geologia estrutural da Bacia de Marajó. 1994. 119 f. Dissertação (Mestrado em Geologia) - Instituto de Geociências, Universidade Federal do Pará, Belém. 1994

ZOVOILI, E.; KONSTANTINIDI, E.; KOUKOUVELAS, I. K. Tectonic geomorphology of escarpments: the cases of Kompotades and Nea Anchialos faults. Bulletin of Geological Society of Greece, v. 36, p. 1716-1725, 2004. 